\section{Appraisal of the practice of ocular self-medication in Cape Coast Metropolis, Ghana}

\author{
Samuel Kyei, ${ }^{1}$ Stephen Ocansey, ${ }^{1,2}$ \\ Emmanuel Kwasi Abu, ${ }^{1}$ \\ Bismark Nyarko Gyedu' \\ 'Department of Optometry, School of \\ Physical Sciences, University of Cape \\ Coast, Ghana; \\ 2Department of Vision and Hearing \\ Sciences, Faculty of Science and \\ Technology, Anglia Ruskin University, \\ Cambridge, UK
}

\begin{abstract}
The purpose of the present study was to assess the practice of ocular self-medication among people of the Cape Coast Metropolis, Central Region of Ghana. A population-based survey involving 421 respondents $\geq 18$ years old was conducted. A pre-tested interview-based questionnaire was used to collect data on demographics, ocular symptoms for which selfmedication was practiced, medical knowledge and self-care orientation. Households were systematically and randomly selected as study units. Analysis was done using SPSS version 16. Descriptive results were expressed as frequency, percentage, and mean \pm standard deviation, $\chi^{2}$ test was used for associations, and logistic regression was used to test for predictors of the practice of ocular self-medication. Prevalence of ocular self-medication was $23.3 \%$ with itchy eye being the main ocular symptom for which self-medication was practiced. Local pharmacies were the main source of drug for ocular self-medication. There was no association between medical knowledge and the practice of ocular self-medication $\left(\chi^{2}=0.126 ; P=0.722\right)$. Some $25.5 \%$ experienced adverse effects. In conclusion, the practice of ocular self-medication was without recourse to adequate concept of the practice of self-care but its negative effect was mitigated by the low self-care orientation of the people.
\end{abstract}

\section{Introduction}

Self-medication, an element of self-care, can be defined as the use of drugs to treat selfdiagnosed disorders or symptoms, or the intermittent or continuous use of a prescribed drug for chronic or recurrent disease or symptoms. ${ }^{1}$ Self-medication has also been defined as obtaining and consuming medication without professional supervision, which comprises acquiring medicine without a prescription, purchasing drugs by resubmitting or reutilising an old prescription, taking medicines on advice of relatives or others, or consuming leftover medicines already available at home. ${ }^{2}$ According to the World Health Organization (WHO) Expert Committee on National Drug policies, self-medication is widely practiced in both developed and developing countries. ${ }^{3-5}$

The practice of self-treatment is a vital part of local medical traditions of African people, where laypeople are used to taking treatment into their own hands on regular basis. ${ }^{6}$ In various situations, familiar illnesses are dealt with by common people (with no medical background) on their own. It is only when the illness shift towards chronicity that people seek expert advice, be it from a local healer or a biomedical experts.

A major deficit of self-medication is the lack of clinical assessment of the health situation by an accredited traditional healer or medical professional, which could result in misdiagnosis and delay in appropriate treatment. ${ }^{7}$ Indiscriminate practice of self-medication results in wastage of resources, ${ }^{8}$ increases resistance of pathogens, ${ }^{7,8}$ and generally entails serious health hazards such as adverse reaction and prolonged suffering. ${ }^{8}$ Some identifiable reasons accounting for the rise in selfmedication is the shift in the pattern of diseases towards chronic ones (30 to $80 \%$ in 40 years) with attendant shift from cure to care. ${ }^{8}$ Several personal factors could also influence self-medication, including sex, income, selfcare orientation, and medication knowledge. ${ }^{9}$ Self-care oriented people are those who undertake activities without professional assistance to promote their own health. ${ }^{9}$ The inadequacies of health care system with its misdistribution of drugs, rising cost and the issue of curative stance of drugs are also worth mentioning. ${ }^{8}$ In developing countries, societies are made of people of diverse ethnic, racial, religious, or social groups who maintain and develop their traditional culture or special interest within the confines of a common civilization. This has made allopathic health care a pluralistic part of the medical system which exists with traditional medicine practices such as consultation with traditional healers and self-medication with herbal preparations. ${ }^{10}$ It has been noted that many prescription pharmaceuticals and traditional herbal eye medications are sold over the counter in developing countries due to laxity of existing regulation regardless of the fact of some of these traditional eye medications are estimated to account for $8-10 \%$ of corneal blindness in Africa. ${ }^{11,12,4,8}$ On the other hand, if done appropriately, self-medication can readily relieve acute medical problems, can save the time spent in waiting to see a doctor, may be economical and can even save lives in acute con-
Correspondence: Samuel Kyei, Department of Optometry, School of Physical Science, University of Cape Coast, 7062 Cape Coast, Ghana.

Tel./Fax: +233243309718 .

E-mail: skyei@ucc.edu.gh

Key words: ocular symptoms, self-medication, adverse effect, Africa.

Acknowledgments: the authors are grateful to Esther Duncan and Dr. Abraham Carl Halladay for their support in typesetting the manuscript.

Received for publication: 1 December 2013. Accepted for publication: 14 March 2014

This work is licensed under a Creative Commons Attribution NonCommercial 3.0 License (CC BYNC 3.0).

(C) Copyright S. Kyei et al., 2014

Licensee PAGEPress, Italy

Optometry Reports 2014; 4:2164

doi:10.4081/optometry.2014.2164

ditions. ${ }^{13}$ It is now accepted by the World Health Organization that self care in the form of responsible self-medication can be beneficial for patients, healthcare providers, the pharmaceutical industry and governments as a means to reduce cost for health care system and the individual citizens. ${ }^{2}$ However, WHO stresses that self-medication can only be used in countries that are able to provide health care and education, and thus empower citizens to self-medicate responsibly..$^{14}$ It is also recognized that self-medication must be accompanied by appropriate health information. ${ }^{13}$ In Ghana, there is dearth of information regarding the practice of self-medication especially in eye care and there are no clear strategy in dealing with this practice, as the situation have not been well evaluated. Hence, describing self-medication practices for ocular disorders among people in the Cape Coast the Central Region of Ghana is very crucial for policy direction and public education.

\section{Materials and Methods}

\section{Study area}

This study was a population based survey, which was conducted in the Cape Coast, Ghana between February and May 2013. Cape Coast is the only district among the 17 districts of the Central Region of Ghana to attain a metropolitan status, and has an estimated population of 169,894 of which males account for $48.74 \%$ and females $51.26 \%{ }^{15}$ About $6 \%$ of settlements in the Metropolis comprising Cape Coast (101,102), Efutu (2720), Ekon (4230), 
Kakumdo (3229), and Nkanfoa (3680) accounts for nearly $85 \%$ of the of the entire metropolitan population. ${ }^{16}$

\section{Sampling technique}

A total of 700 people within these five major communities were sampled. The minimum sample size for the survey was determined as quoted by Glenn ${ }^{17}$ using the following formula:

$$
\mathrm{N}_{0}=\mathrm{Z}^{2} \mathrm{pq} / \mathrm{e}^{2}
$$

where $\mathrm{N}_{0}$ is the sample size, $\mathrm{Z}^{2}$ is the abscissa of the normal curve that cuts off an area $\alpha$ at the tails ( 1 - $\alpha$ equals the desired confidence level), e is the desired level of precision, $\mathrm{P}$ is the estimated proportion of an attribute that is present in the population, q is 1-P.

Therefore, assuming that $50 \%$ of the population will be available for the survey, taking a confidence level of $95 \%$ and a sampling error of $5 \%$ minimum sample size computed was 384 . However, the sample size was adjusted to 700 .

\section{Subject selection}

In each of the five settlements, each household was considered as a study unit. ${ }^{18}$ The first household was randomly selected (based upon the number of households to the edge of the community) from the centre of the community. ${ }^{3}$ Subsequent households were systematically selected based on the number of household needed for that settlement, regardless of direction. Within each household only one person (eldest adult/breadwinner, 18 years and above) was selected for interview using an interviewbased questionnaire. ${ }^{3}$

\section{Data collection procedure}

An interview-based questionnaire with closed and open ended questions was developed in English language, pretested, appropriately modified, before administration to the participants. The questions on the questionnaire were interpreted in the local dialect. The questionnaire consisted of three sections. The first section contained questions regarding demographic information such as gender, age, marital status, religion, occupation, and highest level of education, as well as socioeconomic status. In addition, participants were asked whether they are on the national health insurance scheme. Socioeconomic status was graded based on previous studies. ${ }^{19}$

However, persons engaged in large scale farming and business was assigned either high or medium socioeconomic status. The second section of the questionnaire consisted of questions related to the attitudes towards eye care services and the practice of self-medication. This part was also used to assess respondents' level of self-care orientation. Respondents who indicated that they would treat 5 or more conditions of the presented list were considered to have high self-care orientation, whereas those who selected less than 5 cases were considered to have a low self-care orientation. ${ }^{9}$ The last section was designed to assess respondents' medication knowledge based on Isacson and Bingefors method. ${ }^{9}$

\section{Statistical analysis}

The responses of the interview-based questionnaire were used for the analysis. All the variables were coded, entered, and analysed using the statistical package for social sciences (SPSS) version 16. Descriptive results were expressed as frequency, percentage, and mean \pm standard deviation (SD). Logistic regression was used to identify predictors of ocular self-medication practices among selected variables (gender, level of education, socioeconomic status, self-care orientation, and level of education). $\chi^{2}$ statistical analysis was used to test for significant associations between variables.

\section{Ethical consideration}

The research was done according to the Helsinki Declaration on Research regarding human subjects. A detailed rationale for the study was given to respondents, after which respondents signed a consent form. Confidentiality was ensured and the problems of self-medication were communicated to the respondents after each interview.

\section{Inclusion criteria}

Individuals who have had at least an episode of an ocular disorder a year prior to the conduct of this study and aged 18 years and older were included in the study.

\section{Results}

\section{Socio-demographic characteristics}

Out of the 700 people who consented and were interviewed, $421(60.1 \%)$ met the inclusion criteria; 182 (43.2\%) were males and 239 (56.8\%) were females. Majority of the respondents (50.8\%) were young adults (18-35 years) and the rest were old adults and elderly persons within the age range of $36-59$ years and over 60 years respectively. The age range of the respondents was 18 to 90 years. The mean age \pm SD was $39.81 \pm 18.62$. The marital statuses of the respondents ranged from married to divorced across the different religious background (Table 1).

One hundred and forty four (34.2\%) of the respondents were traders. Seventy four (17.6\%) were students, 67 (15.9\%) were unemployed, 22 (5.2\%) were into fishing, 17 (4.0\%) were public servants, 10 (2.4\%) were crop farmers, and 87 (20.7\%) were into other occupation such as artisanship, hairdressing, driving and tailoring.

The educational background of the respondents who have had episodes of an eye disorder the year under review ranged from no schooling at all to higher education (teacher training college, nursing training college, polytechnic and university) (Table 1).

Three hundred and thirty four (79.3\%) of the respondents were in the low socioeconomic class. Seventy two (17.1\%) were in the middle socioeconomic class and $15(3.6 \%)$ were in the high socioeconomic class. More females (60\%) were on health insurance than males. A total of 245 (58.2\%) were on health insurance, while $176(41.8 \%)$ were not on the national health insurance scheme.

\section{Symptoms of eye disease and the intervention sought}

The respondents reported of 878 multiple ocular symptoms out of which 231 (26.3\%) were itchy eye, 155 (17.7\%) red eye, 155 (13.1\%) painful eye, 96 (10.9\%) teary eye, $126(14.4 \%)$ poor vision, 55 (6.3\%) discharge, $42(4.8 \%)$ headaches, 18 (2.1\%) swollen eye, $16(1.8 \%)$, and 24 (2.7\%) other symptoms like burning sensation, photophobia, blur vision, lid mass, and rainbow around light. Interventions sought by the respondents included visiting a health facility; 137 (32.5\%); practising self-medication, 98 (23.3\%); consulting a traditional healer, 23 (5.5\%); visiting a local pharmacy, 44 (10.5\%) and 119 (28.3\%) did nothing about their condition. Ocular symptoms for which self-medication was practised were painful eye 39 (17.6\%), red eye $54(24.4 \%)$, teary eye $22(10.0 \%)$, discharge 24 (10.9\%), itchy eye 57 (25.8\%), poor vision $5(2.3 \%)$, eye injury 5 (2.3\%), swollen eye $5(2.3 \%)$, headache $5(2.3 \%)$, and other symptoms 5 (2.3\%).

\section{The practice of self-medication}

The frequency of reported episodes of ocular disorders ranged from 1 to 3 times within the year under consideration with an average reportage being 2 issues per year.

Majority of the respondents (54.1\%) who practiced self-medication were the young adults (18-35 years), while those who were 60 years and older were the least (11.2\%) to practice self-medication however, age group was not associated with self-medication $\left(\chi^{2}=3.834\right.$; $\mathrm{P}=0.147)$. Among the sampled male population, $26.3 \%$ of them practised self-medication while $20.9 \%$ of the sampled female population self medicated. Sex was not associated with self-medication $\left(\chi^{2}=1.720 ; \mathrm{P}=0.190\right)$ (Table 2 ). Among the non insured, $33.5 \%$ of them practiced self-medication while $15.9 \%$ of that being health insured practiced self-medication. Association between self-medication and 
health insurance was statistically significant as the non-insured were likely to practice of ocular self-medication $\left(\chi^{2}=17.773 ; \mathrm{P}<0.001\right)$ (Table 2).

The highest percentage of those who did self-medication was in the high socioeconomic class (33.3\%) but association between selfmedication and socioeconomic status was not significant $\left(\chi^{2}=0.905 ; \mathrm{P}=0.636\right)$ (Table 2). With respect to religion, $22 \%$ of the Christian population (363), 30.6\% of the Muslim population (49), $50 \%$ of the traditional religious group (4), and $20 \%$ of those belonging to other religions (5), practiced ocular self-medication. No association was found between religion and the practice of ocular self-medication $\left(\chi^{2}=3.417 ; \mathrm{P}=0.332\right)$ (Table 1).

There was no association between educational level and the practice of ocular self-medication $\left(\chi^{2}=4.347 ; \mathrm{P}=0.361\right)$.
With regards to marital status, $24.2 \%$ of the married (194), $25.6 \%$ of the unmarried (160), $22.7 \%$ of the divorcees (22), $10.3 \%$ of the widowed (39), and $50 \%$ of the separated (2) practiced ocular self-medication. None of those $\mathrm{Co}$ habitating reported practising ocular self-medication. No association was found between marital status and the practice of ocular selfmedication $\left(\chi^{2}=6.311 ; P=0.277\right)$ (Table 1).

Forty seven (48.0\%) of those who practised self-medication, reported local drug store (pharmacy) as their source of medication. Other sources include previous prescriptions, family member's prescription, a friend's prescription, the local sales van and others such as sea water (Table 3 ).

Among the reasons for which self-medication was practised, 45 (32.1\%) was due to the perception that the disease was simple or minor, $33(23.6 \%)$ was due to financial con- straint, 18 (12.9\%) was experience from previous illness, 18 (12.9\%) said because of the desire for quick relief, 10 (7.1\%) was due to advice from neighbours, 6 (4.3\%) was because of longer waiting time at health facilities, 5 (3.5\%) was due to distance from health facility, 4 (2.9\%) was because of lack of trust in medical services, and $1(0.7 \%)$ was due to other reason like the kind of job engaged in. The association between reasons such as experience from previous illness $\left(\chi^{2}=13.654\right.$; $\mathrm{P}<0.001)$, desire for quick relief $\left(\chi^{2}=15.269\right.$; $\mathrm{P}<0.001)$ and self-medication was significant whereas that between simple disease $\left(\chi^{2}=2.301 ; \mathrm{P}=0.129\right)$, lack of trust in medical services $\left(\chi^{2}=0.431 ; \mathrm{P}=0.512\right)$, financial constraint $\left(\chi^{2}=0.015 ; \mathrm{P}=0.901\right)$, advice from neighbours $\left(\chi^{2}=3.767 ; \mathrm{P}=0.052\right)$, distance $\left(\chi^{2}=0.284 ; \mathrm{P}=0.594\right)$, longer waiting time $\left(\chi^{2}=0.211 ; P=0.646\right)$ and self-medication were

Table 1. Distribution of the practice of ocular self-medication by level of educational, religion and marital status.

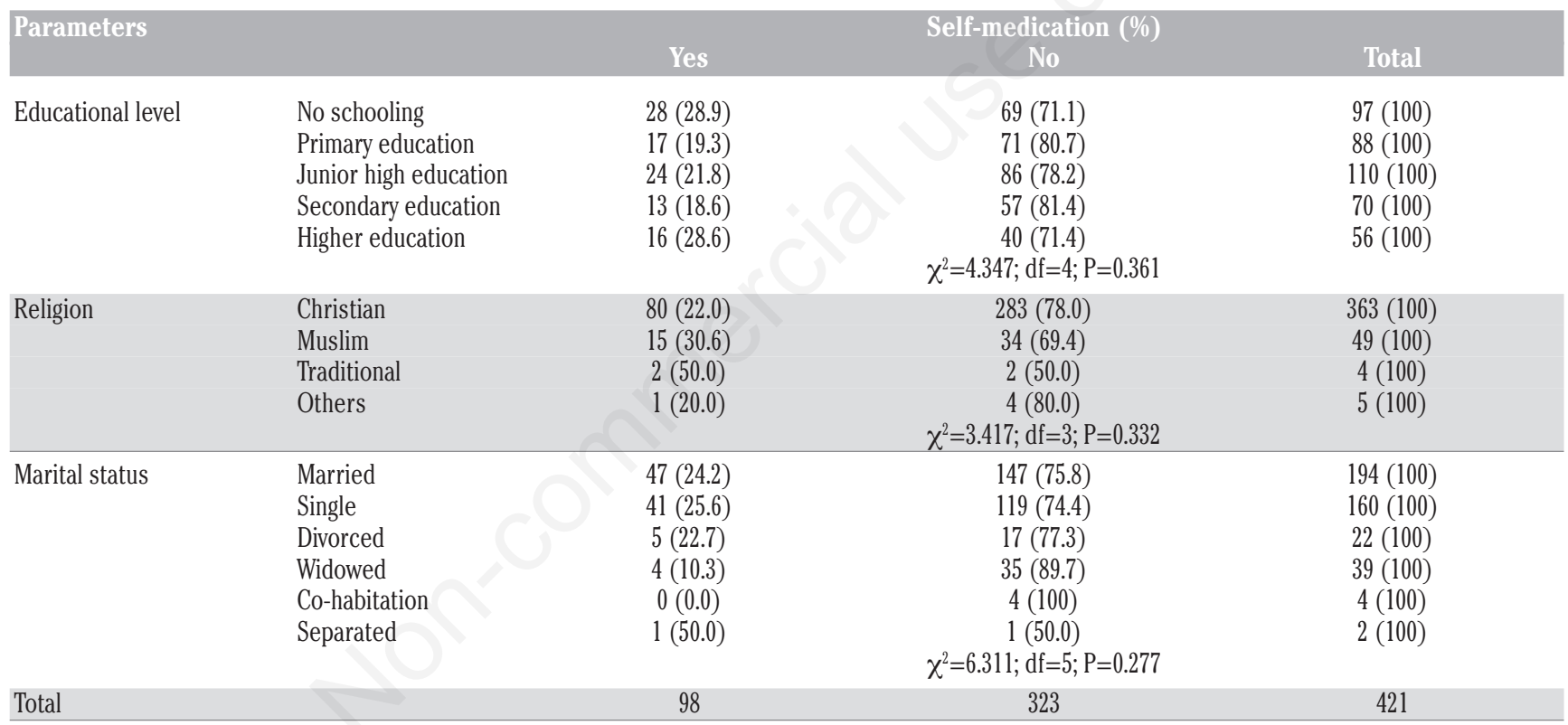

df, degree of freedom.

Table 2. Distribution of the practice of ocular self-medication by sex, health insurance status and socioeconomic status.

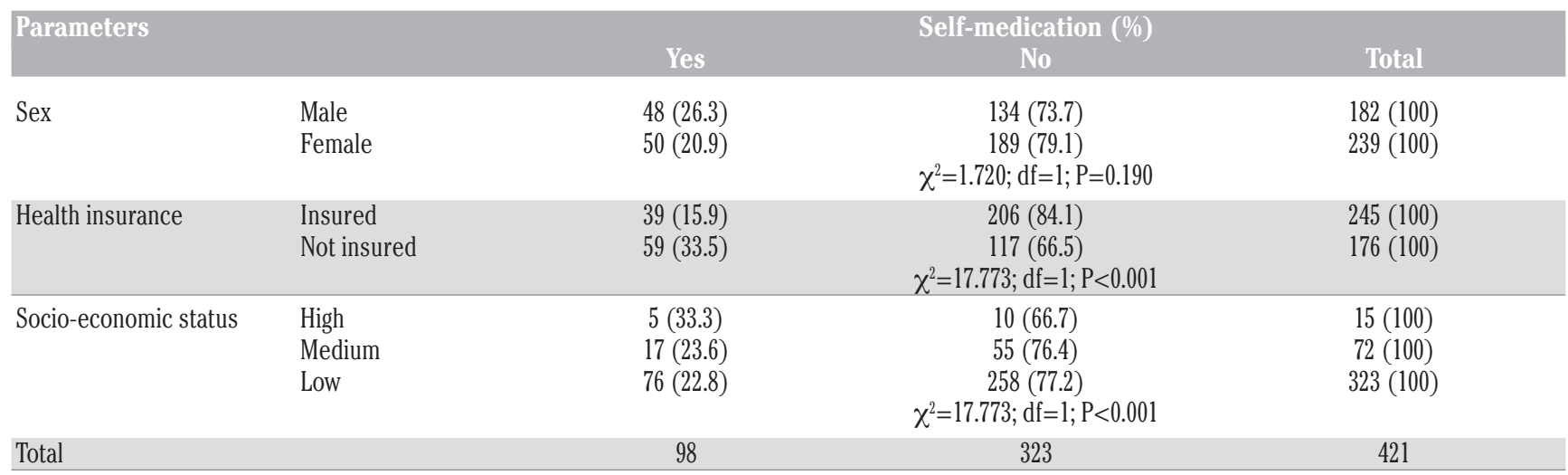

df, degree of freedom. 
not significant.

\section{Self-medication and adverse effects}

Among the 98 (23\%) respondents who practised self-medication, 25 (25.5\%) of them reported having had adverse effects. Among the adverse effects of self-medication were increased pain, excessive tearing, increased irritation, red eye and loss of vision among others. (Table 4). The association between adverse effects such as increased pain $\left(\chi^{2}=0.495\right.$; $\mathrm{P}=0.482)$, corneal ulceration $\quad\left(\chi^{2}=1.074\right.$; $\mathrm{P}=0.300)$, excessive tearing $\quad\left(\chi^{2}=1.210\right.$; $\mathrm{P}=0.271)$, red eye $\left(\chi^{2}=0.742 ; \mathrm{P}=0.389\right)$, loss of vision $\left(\chi^{2}=1.074 ; \mathrm{P}=0.300\right)$, increased irritation $\left(\chi^{2}=0.967 ; \mathrm{P}=0.326\right)$ and self-medication was not statistically significant.

\section{Self-care orientation}

Out of the 421 respondents, 11 (2.6\%) had high self-care orientation, while 410 (97.4\%) had low self-care orientation. The association between self-care orientation and self-medication was statistically significant $\left(\chi^{2}=28.928\right.$; $\mathrm{P}<0.001$ ) (Table 5).

Of the 421 respondents, 299 (71.0\%) had good medical knowledge, while 122 (29.1\%) had poor medical knowledge. The association between medical knowledge and self-medication was not statistically significant $\left(\chi^{2}=0.126\right.$; $\mathrm{P}=0.772$ ) (Table 5). Variables like occupation, educational level, self-care orientation, experience from previous ocular illness, quick relief and health insurance had an association with self-medication when all factor analysis with logistic regression was performed. When further logistic regression analysis was done on variables such as health insurance, experience from previous ocular illness, quick relief, and self-care orientation, it was statistically significant $(\mathrm{P}<0.05)$ (Table 6).

\section{Discussion}

Although self-medication is an old practice, it has recently drawn the attention of health care scientists in many settings..$^{3,4,20-22}$ In Ghana, the practice is yet to receive outermost attention particularly in eye care as there are few recent studies into this subject matter regarding antibiotic use and ocular self-medication practices. ${ }^{23}$ Several methods have been employed in the study of the practice of selfmedication but this study ${ }^{3}$ employed systematic random sampling to select participants. The study design has the strength of being population-based; however, care should be taken in applying the results as there are socio-cultural variations across the globe. ${ }^{24}$ The prevalence of ocular self-medication among inhabitants of the Cape Coast is comparable to that in Ibadan, Nigeria $^{25}$ and some three towns of North West Ethiopia ${ }^{26}$ indicating that practice is prevalent in comparable proportions across the continent. This phenomenon is reported as the first option approach among some rural African popuation. $^{3}$

The progressive decline in the practice of ocular self-medication from the youthful ages to late adulthood could be due to the risk prone

Table 3. Sources of drug for ocular self-medication.

\begin{tabular}{lcc} 
Source & Frequency & $\%$ \\
Prescription from previous illness & 15 & 15.3 \\
Local sales vans & 6 & 6.1 \\
\hline Family member's prescription & 12 & 12.2 \\
Friend's prescription & 8 & 8.2 \\
\hline Local drug store (pharmacy) & 47 & 48.0 \\
Others & 10 & 10.2 \\
\hline Total & 98 & 100.0 \\
\hline
\end{tabular}

Table 4. Adverse effects of self-medication.

\begin{tabular}{lcc} 
Adverse effects & Frequency & $\%$ \\
Increased pain & 17 & 45.9 \\
Cornea ulcer & 2 & 5.4 \\
\hline Excessive tearing & 6 & 16.2 \\
Red eye & 4 & 10.8 \\
\hline Loss of vision & 2 & 5.4 \\
Increased irritation & 5 & 13.5 \\
\hline Others & 1 & 2.7 \\
Total & 37 & 100 \\
\hline
\end{tabular}

Table 5. Distribution of respondents by self-care orientation and medical knowledge.

\begin{tabular}{llccc} 
Parameters & \multicolumn{3}{c}{ Yes } & No \\
& & $10(90.9)$ & $1(9.1)$ & $11(100)$ \\
Self-care orientation & High & $88(21.5)$ & $322(78.5)$ & $410(100)$ \\
& Low & & $\chi^{2}=28.928 ; \mathrm{df}=1 ; \mathrm{P}<0.001$ & \\
Medical knowledge & Good & $71(23.7)$ & $228(76.3)$ & $299(100)$ \\
& Poor & $27(22.1)$ & $95(77.9)$ & $122(100)$ \\
& & & $\chi^{2}=28.928 ; \mathrm{df}=1 ; \mathrm{P}<0.001$ & \\
\hline
\end{tabular}

Table 6. Factors influencing self-medication.

\begin{tabular}{|c|c|c|c|c|c|c|c|c|}
\hline & \multirow[t]{2}{*}{ B } & \multirow[t]{2}{*}{ SE } & \multirow[t]{2}{*}{ Wald } & \multirow[t]{2}{*}{ df } & \multirow[t]{2}{*}{$\mathbf{P}$} & \multirow[t]{2}{*}{ EXP B } & \multicolumn{2}{|c|}{$95 \%$ CI for EXP B } \\
\hline & & & & & & & Lower & Upper \\
\hline High orientation & -3.073 & 0.079 & 8.118 & 1 & 0.004 & 0.046 & 0.006 & 0.383 \\
\hline Experience & -1.635 & 0.457 & 12.775 & 1 & 0.000 & 0.195 & 0.080 & 0.478 \\
\hline Quick relief & -1.713 & 0.471 & 13.256 & 1 & 0.000 & 0.180 & 0.072 & 0.453 \\
\hline Not insured & 0.740 & 0.278 & 7.076 & 1 & 0.008 & 2.096 & 1.215 & 3.616 \\
\hline Constant & 4.952 & 1.254 & 15.601 & 1 & 0.000 & 141.488 & - & - \\
\hline
\end{tabular}

B, constant; SE, standard error; df, degree of freedom. 
attitude associated with youthfulness ${ }^{18}$ or their being more aware of their ocular health needs.$^{27}$ Again, as individuals grow older their frequency of visit to the doctor ${ }^{23}$ for general health check-up tend to increase and as a result ocular complaints are taken care of. Despite the higher proportion of male practicing self-medication than their female counterparts, the practice is not dependent on sex. ${ }^{28}$ Among the sampled socioeconomic statuses, those in the high socioeconomic class constituted the highest percentage of those who practiced self-medication. Economic factors have long been associated with self-medication in several jurisdictions. ${ }^{29}$ This implies that the socioeconomic state has a likely implication on drug consumption habit. However, this study found no association between the sampled socioeconomic statuses and the practice of ocular self-medication despite the higher percentage of those practicing self-medication the high socioeconomic class. This is largely so as it has been asserted that individuals in the high socioeconomic class are more aware of their ocular health needs and as a result tend to practice self-care. ${ }^{30}$

Although majority of the population who practiced ocular self-medication had good medical knowledge (71, 72.4\%), having good medical knowledge was not associated with the practising of self-medication $(\mathrm{P}=0.772)$. As expected, good medical knowledge is associated with rational use of drug and a very essential prerequisite for reasonable self-care practices, ${ }^{31}$ but the practice of ocular self-medication among this population was without recourse to adequate knowledge. However, the low self-care orientation might have impacted the prevalence of ocular self-medication practice. This is because the low self-care orientation means that their tendency to practice ocular self-medication was minimal thereby reducing the risk associated uninformed practice of ocular self-medication.

Ocular complaint for which self-medication was practiced was teary eye, discharge, swollen eye, trauma to the eye, poor vision, and headaches. Similar complaints have been reported among Africans. ${ }^{32}$ However, individuals with ocular symptoms such as red eye, painful eyes, discharge, and poor vision (in order of frequency) are more likely to practice self-medication than itchy eye $(\mathrm{P}<0.05)$. Most of these symptoms that prompt the practice of ocular self-medication could be attributed to infectious and inflammatory disorders of the eye such as conjuctivitis. ${ }^{3}$

The pharmacies served as the major access point for medication for the practice of ocular self-medication. The drugs from local pharmacies are obtained by the use of old prescriptions, showing samples of similar ocular medication needed, or mentioning the name of the eye medication needed. ${ }^{4,32-34}$
The major reason for practising ocular selfmedication was the perception that the symptoms experienced were of a minor/simple disorder and warranted no expert care. Such assumptions for self-medication have been cited. ${ }^{4,6}$ This is a dangerous assumption as minor ailments that could be managed by a health professional could easily be mismanaged through self-medication. Financial constraint, experience from previous ocular episode, quick relief, longer waiting time at health facilities, lack of trust in medical services, advice from neighbours, and distance to health facilities are other reasons for which ocular self-medication was practiced. Although the perception that a particular ocular symptom was of simple disease and financial constraint (cost) were the major reasons given for the practice of self-medication, an individual with a previous experience of an ocular illness, and the desire for quick relief are more likely factors for which an individual may practice ocular self-medication $(\mathrm{P}<0.001)$. Distance to health facilities was amongst the least reasons for which self-medication would be practised contrary to studies by Godeliver et $a l .^{32}$ and Van den Boom et al. ${ }^{35}$

Logistic regression analysis indicated that high self-care orientation, not having health insurance, experience from previous ocular episode, and quick relief were the four key factors that influenced the practice of ocular selfmedication $(\mathrm{P}<0.05)$. The practice of ocular self -medication was not without issue among a fourth of those engaged in the practise. These adverse effects were mainly painful eyes, but included loss of vision, red eye, corneal ulceration, burning sensation, and increased irritation. This could be due to practising self-medication regardless of one's medical knowledge,${ }^{31}$ however, the lack of association between self-medication and adverse reaction $(\mathrm{P}=0.482)$ could be explained by the low self-care orientation of the people limiting the tendency of the practice.

\section{Conclusions}

The practice of ocular self-medication in Cape Coast Metropolis, Ghana is without recourse to adequate recommendation by the WHO regarding reasonably adoption of the practice. Public health education should therefore be stepped up regarding the rational practice of ocular self-medication.

\section{References}

1. WHO. Guidelines for the regulatory assessment of medicinal products for use in self-medication 2000. Geneva, Switzerland: World Health Organization; 2000. Available from: http://apps.who.int/ medicinedocs/pdf/s2218e/s2218e.pdf

2. Gupta V, Bansal P, Manhas R, et al. Preferred system of medicine and reasons of self-medication among college students in malwa region of Punjab. Available from: http://jddtonline.info/index.php/jddt/article/view/41/18

3. WHO. How to investigate drug use in health facilities. Geneva, Switzerland: World Health Organization; 2000. Available from: http://apps.who.int/medicinedocs/ pdf/s2289e/s2289e.pdf

4. Bisika T, Courtright P, Geneau R, et al. Self treatment of eye diseases in malawi. Afr $\mathrm{J}$ Tradit Complem 2009;6:23-9.

5. Omolase CO, Afolabi AO, Omolase BO. Ocular self-medication in Owo, Nigeria. Nig J Postgrad Med 2008;1:8-14.

6. Omolase CO, Adeleke OE, Afolabi AO, Afolabi OT. Self-medication amongst general outpatients in a Nigerian community hospital. Available from: http://www.ajol. info/index.php/aipm/arti cle/viewFile/ 64032/51832

7. Worku S, Abebe GM. Practice of self-medication in Jimma Town. Available from: http://ejhd.uib.no/ejhdv17-no2/ejhdv17n2page111.pdf

8. Sonam J, Reetesh M, Jeetendra KP. Concept of self-medication: a review. Int $\mathrm{J}$ Pharm Biol Arch 2011;2:831-6.

9. Ansam FS. A Descriptive study of self-medication practices among Palestinian medical and non medical university students. Res Social Adm Pharm 2008;4:164-72.

10. Vandebroek I, Calewaert JB, De jonckheere $\mathrm{S}$, et al. Use of medicinal plants and pharmaceuticals by indigenous communities in the Bolivian Andes and Amazon. Available from: http://apps.who.int/iris/bitstream/10665/72361/1/bulletin_ 2004_82\%284\%29_243-250.pdf?ua=1

11. Verma RK, Mohan L, Pandey M. Evaluation of self-medication among professional students in North India: proper statutory drug control must be implemented. Available from: http://www.ajpcr.com/Vol3Issuel/ 270.pdf

12. Kadri R, Hegde S, Kudva AA, et al. Selfmedication with over the counter ophthalmic preparations: is it safe? Available from: http://www.biomedscidirect.com/ journalfiles/IJBMRF2010130/self_medication_with_over_the_counter_ophthalmic_preparations_is_it_safe.pdf

13. Mumtaz Y, Jahangeer SMA, Mujtaba T, et al. Self-medication among University students of Karachi. Available from: http://www.lumhs.edu.pk/jlumhs/Vol10No0 3/pdfs/v10n3oa13.pdf

14. Corrêa da Silva MG, Soares MCF, Muccillo- 
Baisch AL. Self-medication in university students from the city of Rio Grande, Brazil. BMC Public Health 2012;12:339.

15. Ghana Statistical Service. 2010 population and housing census. Final results. Available from: http://www.statsghana. gov.gh/docfiles/2010phc/2010_POPULATION_AND_HOUSING_CENSUS_FINAL_ RESULTS.pdf

16. Cape Coast Metropolitan Assembly. Strategic environmental assessment (SEA) of MTDP 2010-2013. Cape Coast, Ghana: Cape Coast Metropolitan Assembly Publ.; 2010.

17. Glenn DI. Determinig sample size. Sampling the evidence of extension program impact, PEOD-5. 1992. Available from: http://edis.ifas.ufl.edu/pd006

18. Gupta P, Bobhate PS, Shrivastava SR. Determinants of self-medication practices in an urban slum community. Available from: http://www.ajpcr.com/Vol4Issue3/ 346.pdf

19. Vyas S, Kumaranayake L. Constructing socio-economic status indices: how to use principal components analysis. Health Policy Plann 2006;21:459-68.

20. Blenkinsopp A, Bradley C. Patients, society and the increase in self-medication. Brit Med J 1996;9:629-32.

21. Kadri R, Hegde S, Kudva AA, et al. Selfmedication with over the counter oph- thalmic preparations: is it safe? Int J Biol Med Res 2011;2:528-30.

22. Afolabi A0. Self-medication, drug dependency and self-managed health care. A review. In: Maddock J, ed. Public health: social and behavioral health. Rijeka, Croatia: InTech; 2012. pp 223-42.

23. Donkor ES, Tetteh-Quarcoo PB, Nartey P, Agyeman IO. Self-medication practices with antibiotics among tertiary level students in Accra, Ghana: a cross-sectional study. Int J Environ Res 2012;9:3519-29.

24. Souza Carvalho R, Kara-José N, NomaCampos R. Self-medication: initial treatments used by patients seen in an ophthalmologic emergency room. Clinics 2009: $735-41$.

25. Ajaiyeoba AI, Scott SCO. Risk factors associated with eye diseases in Ibadan, Nigeria. Afr J Biomed Res 2002;5:1-3.

26. Abula T, Worku A. Self-medication in three towns of North West Ethiopia. Ethiop J Health Dev 2001;15:25-30.

27. Baig S. Self-medication practices. Prof Med J 2012;19:513-21.

28. Klemenc-Keti Z, Hladnik Z, Kersnik J. A cross sectional study of sex differences in self-medication practices among university students in Slovenia. Collegium Antropol 2011;2:329-34.

29. Nancy V, Markm N. Changing patterns of pharmaceutical practice in the United
States. Soc Sci Med 1997;44:1285-302.

30. Larrañaga I, Santa-Marina L, Begiristain $\mathrm{H}$, et al. Socio-economic inequalities in health, habits and self-care during pregnancy in Spain. Matern Child Health J 2013;17:1315-24.

31. Calamusa A, Marzio A, Cristofani R, et al. Factors that influence Italian consumers' understanding of over-the-counter medicines and risk perception. Patient Educ Couns 2012;87:395-401.

32. Kagashe GAB, Msela B. Self-medication among patients seen at Ophthalmology Clinics at four hospitals in Dar Es Salaam Tanzania. Available from: http://www.iosrphr.org/papers/v2i5/Part_5/D0252125.pdf

33. Abay SM, Amelo W. Assessment of selfmedication practices among medical, pharmacy, and health science students in Gondar University, Ethiopia. J Young Pharm. 2010;2:306-10.

34. El Sharief SI, Ibrahim OHM, Mouslli L, Waisi R. Evaluation of self-medication among pharmacy students. Am J Pharmacol Toxicol 2012;7:135-40.

35. Van den Boom GJM, Nsowah-Nuamah NNN, Overbosch GB. Curative health care utilization in Ghana: a multinomial analysis of equitable access opportunities. Available from: http://www.sow.vu.nl/ pdf/wp02-01.PDF 